\title{
AN ECONOMIC STUDY OF NASONIA BREVICORNIS, A HYMENOPTEROUS PARASITE OF MUSCID DIPTERA.
}

\section{By John L. Froggatt, B.Sc.}

In considering the methods of coping with any group of injurious insects, the study of natural enemies must occupy an important place in any laboratory or field investigations that are carried out in connection with such pests.

When investigations concerning the sheep-maggot fly pest were commenced in New South Wales in 1913, careful search was made for any natural enemies in the field, and in November of that year pupae of Pycnosoma (Calliphora) rufffacies were found heavily parasitised by a small Chalcid wasp. This discovery was made on Yarrawin Station (Messrs. Dickson Bros.) in the Brewarrina district, under the remains of a dead foal. The carcase was lying on the edge of a patch of scalded ground, with a little timber about 100 yards away. On pulling the remains apart, a large number of pupae of Pycnosoma rufifacies were exposed; from some the flies had already emerged, many others were intact. Some of the intact pupae were carefully opened with the point of a penknife, and were found to contain a number of small, white, creamy, brown or black objects, these being the larvae, early pupal, and late pupal stages of the parasite wasps. A few of the intact pupae that could be found were collected for further study and observation; some were retained at the Experiment Station, and the remainder taken to the Entomological Department, Sydney. An average count of a number of these parasitised pupae gave the result of about 20 wasps per pupa.

Before proceeding further, a consideration of the distribution of this wasp should prove of interest: Within a few days of the above-mentioned discovery this parasite was found under similar circumstances at Longreach, Central Queensland. Specimens of the wasp sent to Dr. Howard, Chief of the Bureau of Entomology, Washington, U.S.A., by the Government Entomologist of New South Wales were identified as Nasonia brevicornis, a Hymenopterous parasite that had been originally described by Messrs. Girault \& Saunders, who bred it from the pupae of the common house-fly (Musca domestica) at the Illinois Entomological Station at Urbana in 1908. It has also been reported from Chili ; and the British Museum has received specimens of it from India. Future researches may reveal that its range is only restricted by the distribution of the Muscid flies.

Further observations in New South Wales have shown that it is only scattered thinly over most parts of this State and is doing valuable work in preventing the breeding of the flies by their destruction in the pupal condition. Probably it is to be found over the greater part of Australia.

The breeding of these wasps has been carried on continuously and systematically from those bred from the parasitised pupae in November 1913, the wasps now being used in the cages for the purposes of propagation being the direct progeny of those obtained from the original lot of pupae. On a few occasions additions have been made by introducing fresh specimens of Nasonia brevicornis collected in the field. (See paper in the Agricultural Gazette of N. S. Wales, September 1914, McCarthy's observations).

(C507) 
The economic value of this parasite has proved to be so great, where found actively at work in the field, that a more extensive means of artificially propagating the wasps on a large scale-by laboratory breeding and subsequent distribution-has been undertaken. This work has now assumed large proportions and is still extending. Under present arrangements, fifty thousand fresh pupae can be parasitised per week. Some idea of the extent of the work may be gathered from the following facts :-

Between November 1917 and 14th February 1918, 164 packets of parasitised pupae, averaging approximately 10,000 parasites per packet, have been distributed; while fully as many have been liberated (i.e., approximately 1,500,000 live parasites) on Kooroogama Station, Moree. Large numbers of parasitised pupae have also been held back for work in the breeding cages. Over 200 fresh requests from all parts of Australia are now waiting to be fulfilled and other requests are being received daily.

In view of the importance of this work from an economic point of view, an account of the operations, with a few notes on the habits of the wasp observed in both the field and laboratory, are herewith recorded.

The work of breeding the parasites is completely carried out in cages 12 inches long, 12 inches high and $8 \frac{1}{2}$ inches wide. The bottom and one side of the cage are made of wood, the other side and one end of glass, while the top and the other end are covered with very fine mesh copper gauze; the door occupies the whole wire gauze end and is hinged to open outwards. Around the door, inside the cage, a light beading is fixed, and so prevents the tiny wasps from escaping through any crack between the door and the cage. If the beading is not present, paper must be pasted round the door. Any cracks or spaces must, of course, be also pasted over.

A tray of one-tenth inch mesh wire gauze is placed in the bottom of the cage ; and, on this, a light paper tray is placed, upon which the unparasitised pupae are spread. The wire gauze tray should be made of such a size as to admit of its easy removal from the cage. From a tack driven into the upper part of the wooden side, a bag of mosquito net containing parasitised pupae, from which the wasps are just emerging, is suspended. Through the mosquito netting the wasps escape into the cage and find the unparasitised pupae.

When the freshly parasitised pupae are ready to be removed from the cage, they are tilted from the paper into the wire gauze tray, upon which they are gently rolled in order to shake all the live wasps into the bottom of the cage, this being done wholly inside the cage. The tray is then removed from the cage and the parasitised pupae set aside, after which the wire gauze and paper trays are replaced in the cage and fresh pupae added. The freshly parasitised pupae, when removed from the breeding cage, are placed in shallow trays for 2 or 3 days to allow them to dry before being either placed in jars or distributed. If placed in jars immediately, the moisture given off is sufficient to saturate them with the accumulated water and so to kill the immature wasps within the pupal shell.

The whole of the operation of transferring and changing the pupae should be done in front of a window and with the glass end of the cage placed towards the light. The wasps are strongly attracted to light and so will make toward the end of the cage farthest from the door, thus obviating any loss of parasites. 
The separation of the pupae from the live parasites inside the cage prevents any loss of the wasps and also prevents any unnecessary handling and knocking about; for they would otherwise have to be recaptured from off the windows.

Feeding the parasites in the cages is effected by placing small strips of calico damped with honey on the glass end and sides to which they will readily adhere. The wasps feed greedily from these strips, which are damped with honey and water at least once a day, and in hot weather two or three times. The strips should be removed every few days and fresh ones used. The old strips can be washed and used again, but they need to be boiled.

The cages, particularly during the hotter months of the year, must be kept in as cool a place as possible and must never be shut out of a free current of air. Moreover, they should be placed in a bright situation, the wasps working much better when the cages are in a good light.

The parasitised pupae are always held for a few days before being distributed, in order to make certain that no flies will develop from the material; as a rule not $\frac{1}{2}$ per cent. of flies breed out from pupae put through the breeding cage. The pupae to be kept for cage breeding work are then placed in jars and the remainder distributed.

About 400 parasitised pupae are placed in the cage for breeding purposes at each addition; and the approximate average number of parasites per pupa is 20 , this gives about 8,000 parasites per cage.

The length of time in which the pupae to be parasitised are kept in the breeding cages varies considerably with climatic conditions. A period of three days is generally sufficient in warm weather, but in cool weather the time is much extended. With experience it is not necessary to examine the pupae to make sure that they are parasitised; the behaviour of the live wasps themselves shows when they have finished with any one lot of pupae.

More work is entailed in breeding fly larvae, in separating them from the breeding material, and in sorting out the fresh pupae. The principal source of supply is from the larvae of the four species, Anastellorhina (Calliphora) augur, Pollenia stygia (Calliphora villosa), Pycnosoma (Calliphora) rufffacies, Lucilia sericata, and also to a lesser extent, Sarcophaga aurifrons. The larvae of Ophyra nigra and Pycnosoma (Calliphora) varipes are also used in an emergency; but it has been found that the pupae of these two species are not selected for parasitism so readily by the wasps as the former species. The larvae of all the first four species breed only in animal material. After extensive trials liver has proved to breed the greatest number of fly larvae per unit weight as compared with other portions of a carcase; and when well "blown" there is little or no waste with it; and furthermore, the larvae are always well grown. From a single bullock's liver over 14,000 larvae of Anastellorhina augur and Pollenia stygia have been obtained at the Experiment Station.

One fact that should always be borne in mind when sorting the larvae is, that the "smooth" larvae (Anastellorhina augur, Pollenia stygia, Lucilia sericata) must be kept in separate receptacles from the " hairy" larvae (Pycnosoma ruffifacies and $P$. varipes), and the larvae of Ophyra nigra must be kept apart from all the above, for the hairy larvae will attack and devour the " smooth" larvae, and the larvae of Ophyra nigra will attack all species. 
Kerosene tins have been used as receptacles for containing the liver during the development of the fly larvae, as these are easily procurable and also cheap. About 4 to 5 inches of fine earth sifted through one-tenth inch mesh wire gauze are placed in the bottom of the tin, and the liver, well slashed with a knife, is then placed on the earth. The earth in the tin serves two purposes:- It absorbs the putrefactive juices from the liver which, if allowed to accumulate, would drown the maggots ; and it also forms a clean dry place for the larvae to crawl into when they have finished feeding and have left the remains of the liver. Should the liver appear to be becoming moist on the top, or should the earth underneath become wet before the larvae have reached maturity, more dry sifted earth must be added. The greatest care and attention is paid to this portion of the work; otherwise the mortality amongst the larvae would be very high. As soon as the majority of the larvae have crawled into the dry earth the remains of the liver are transferred to another tin and the larvae are separated from the more or less damp earth. It is here that the value of the sifted earth is seen, for it affords a rapid separation by allowing the maggots to be sifted without too much knocking about, a happening to be most carefully avoided at all times. The larvae, together with any dirt that will not pass through the sieve, are then placed in a flat shallow pentagonal tray, the apex of the pentagon being cut off to form a narrow opening. The trays are made of tin. The open end should be placed away from the light and the material in the tray stirred about or spread out in a thin layer. The larvae will crawl out and away from the light, falling into oblong tins containing dry sifted earth which are placed under the open end of the tray. These oblong tins (about 12 inches by 8 inches by $3 \frac{1}{2}$ inches high) should be kept covered with wire gauze, to prevent insects and mice from destroying the larvae or pupae. Amongst the insects that have to be thus contended with are:-Dermestes cadaverinus (skin beetle), Creophilus erythrocephalus (devil's coach-horse), Saprinus laetus (shining histerid) and Necrobia rufipes (red-legged ham beetle).

The method of separating the pupae from the larvae is similar to that for separating the larvae from the earth in the breeding tins. The larvae and pupae are sifted out and placed in the sorting trays ; the larvae will crawl away and the pupae will be left behind. By using the trays several lots can be separated at the same time and with little or no rough handling of either the larvae or pupae.

A matter which is most important, but for which as yet no reason can be assigned, is the fact that occasionally a very large percentage of the fly pupae atrophy, the pupal fly rotting and finally drying up. It was thought in the early stages of these investigations that this might have been caused by damage done to the maggots or pupae during sorting, for our methods were not so much simplified as they are now ; but still even now it is found to occur. Furthermore, on a number of occasions deaths of pupae from this cause have been observed in the field where the carcases have never been disturbed.

It is generally amongst the pupae of Pycnosoma rufifacies, and to a lesser extent $P$. varipes, that this species of Chalcid wasp is found actually at work in the field. This is largely due to the habits of the larvae of these two species, which do not crawl away from a carcase to pupate unless the remains have been much disturbed, but pupate either just under the edge of the remains or else affix themselves to the bones, 
wool or other portions of the carcase, and thus they are more easily found than the other species, all of which generally crawl a considerable distance from the carcase and scatter. Where the pupae of these species have been taken while radiating away from carcases, during February to April and during August to October or even into November, they have often been found heavily parasitised by Nasonia brevicornis.

In the laboratory, it has been found that the pupae of Anastellorhina augur, Pollenia stygia, Lucilia sericata, and, when obtainable, Calliphora erythrocephala and Sarcophaga aurifrons (i.e., the "smooth" pupae) are attacked by the wasps before the pupae of Pycnosoma rufifacies. This is probably due to the shell of the pupa being thinner in the former five species than in the latter and thus more easily perforated.

No definite reason can yet be assigned to the apparent distaste of the wasps for the pupae of Ophyra nigra and Pycnosoma varipes in the laboratory. In the field the pupae of the latter species are practically always found to be parasitised.

The actions of the female wasp when placed with the pupae are very interesting. She first crawls over and over them, her body and antennae twitching constantly. She continually touches the pupae with her antennae, as if seeking for the thinnest part of the shell to puncture. When she has finally decided on the spot to be punctured, the tip of the body is curved downwards and the point of the ovipositor is inserted. The apex of the abdomen is then brought back almost to its normal position, and by so doing the whole length of the ovipositor is exposed, its normal position being in a groove along the ventral plates of the abdomen. From this time the body, except for a slight twitching, remains practically motionless, although the antennae are waving continuously. The ovipositor is gradually inserted, apparently by an upward and downward movement of the styles within the sheath. When fully inserted it remains in that position for perhaps a minute, when it is withdrawn about half its length and is again pushed in. This may occur several times, until at last the whole ovipositor is withdrawn and springs back to its normal position.

After the ovipositor is withdrawn a small globule of liquid is observed where the puncture had been made. The liquid is either a fluid resembling in its nature a synovial fluid, or else it had been acting as a lubricant for the styles; the former is the more probable. The female almost immediately turns round and sucks up this liquid and after this there is practically no visible sign of the pupa having been perforated, until the spot dries, when a tiny white dot on the pupal shell is seen where the puncture had been made.

The time occupied for the whole process of insertion, deposition and withdrawal is very variable. The two extremes which have been noted are 4 minutes and 25 minutes. Although the female may attempt to puncture the shell in one spot, she may leave it and make more than one choice of a fresh point before beginning definitely to pierce the pupal shell.

The position of the body during the process of oviposition is characteristic, being arched from the head to the tip of the abdomen with the ovipositor projecting straight down from the mid-ventral surface of the abdomen.

In considering the economic value of these parasites when bred in centres for distribution, the length of time they live under certain conditions becomes a most 
important point. It is already known that the life-cycle is 11 to 14 days under normal conditions. This allows about 8 days from the date of despatch before they hatch out. Therefore the length of time that the wasps will live, after emerging from the pupae, in a closed space (1) without food, (2) with food, become important factors.

(1) As the work of breeding the parasite for distribution will always be more or less localised in centres, from which the parasitised pupae will be sent out, a greater or less time will be occupied in transit of each packet of pupae to its destination, possibly resulting in some cases in the wasps hatching out before completing their journey. In order to determine how long the wasps could live in a confined space without food, a number of parasitised pupae were placed in glass cylinders, the tops of which were covered with muslin. The dates of first emergence and of first deaths were noted, as also the dates when the greatest number of the wasps had hatched out and of the last deaths. This is not strictly identical with the conditions in which the parasitised pupae are sent out, but it at least gives some idea of an answer to this point of investigation. Under these conditions the wasps were found to live from 4 to 6 days.

(2) This is important, owing to the fact that the pastoralists, to whom parasites are sent, are directed to feed the wasps for some days in bottles if no suitable carcase is available on the emergence of the wasps from the pupae. To investigate this point, a number of parasitised pupae were placed in glass cylinders similar to those used above, the tops of the cylinders being covered with muslin. As soon as the wasps emerged, the muslin coverings were damped with honey and water as required. The dates of first emergence, maximum number of parasites bred out, and of first and last deaths were noted. The life of the wasps under these conditions was found to be from 18 to 20 days.

When kept actively parasitising in the breeding cages, the wasps live and work for from 4 to 6 weeks, living longer in the cooler weather. The difference in the length of the life of the wasps kept in a confined space, and of those actively at work in the cages may be due partly to the direct effects of confinement; but in the writer's opinion, it is due more to overcopulation of the females in the confined spaces.

The imago and life-history of this wasp have been previously described by Girault \& Saunders (Psyche, Dec. 1909), and again by W. W. Froggatt and T. McCarthy, in the Agricultural Gazette of N.S.W., and re-published in Farmer's Bulletin No. 95 (Dept. of Agriculture N.S.W.), so that no further account is necessary here.

In conclusion, it might be pointed out that it is seldom that such a hardy and easily bred parasite as Nasonia brevicornis has been found. As has been shown in these notes, given a plentiful supply of fly pupae, unlimited numbers of these little parasites can be artificially bred and distributed. As they remain in the pupae a considerable time, they can be despatched long distances without very much danger of premature emergence, and with ordinary care they can be fed and kept for days before liberation; also while actively parasitising in captivity, they will live for weeks. It is therefore reasonable to expect that this parasite should prove a very important factor in the control and reduction of blowflies and even other species of Diptera. 